\title{
A New Stator Winding Inter-Turn Short Circuit Fault Detection Method For Brushless Doubly Fed Induction Machine
}

\author{
$1^{\text {st }}$ Mojtaba Afshar \\ Department of Electrical and \\ Biomedical Engineering \\ University of Nevada Reno, \\ Reno, NV, USA \\ mojtabaa@unr.edu
}

\author{
$2^{\text {nd }}$ Salman Abdi \\ School of Engineering \\ University of East Anglia, \\ Norwich, UK \\ s.abdi.jalebi@gmail.com
}

\author{
$3^{\text {rd }}$ Abolfazl Mortazavizadeh \\ Department of Electrical and \\ Computer Engineering \\ Isfahan University of Technology, \\ Isfahan, Iran \\ mortazavi1369@gmail.com
}

\author{
$4^{\text {th }}$ Poria Fajri \\ Department of Electrical and \\ Biomedical Engineering \\ University of Nevada Reno, \\ Reno, NV, USA \\ pfajri@unr.edu
}

\author{
$5^{\text {th }}$ Mohammad Ebrahimi \\ Department of Electrical and \\ Computer Engineering \\ Isfahan University of Technology, \\ Isfahan, iran \\ mebrahim@cc.iut.ac.ir
}

\begin{abstract}
The brushless Doubly Fed Induction Machine (BDFIM) with high reliability and robust structure demonstrates technical and commercial advantages both as a generator and motor for variable speed drive applications. As a generator it is particularly attractive to be used in offshore wind turbines where reliability improvement and maintenance cost reduction are the key factors in wind power market growth. As a motor it can be utilized in application requiring adjustable speed operation. Inter-turn short circuit fault is one of the most frequent electrical faults in electric machines, which can also be the cause of other stator winding faults in the machine, hence its early detection can significantly reduce the maintenance cost and improve reliability. In this paper a novel fault detection method for inter-turn short circuit fault is proposed for the BDFIM based on the discrete wavelet transform of the stator winding currents. The analytical winding function method as well as the finite element analysis of an experimental D180 BDFIM is used in order to verify the proposed fault detection method.
\end{abstract}

Index Terms-Brushless Doubly Fed Induction Machin (BDFIM), condition monitoring, fault detection, Motor Current Signature Analysis (MCSA), signal processing, wavelet transform.

\section{INTRODUCTION}

Brushless Doubly Fed Induction Machines (BDFIMs) offer promising design features and performance characteristics such as brushless structure, slip ring elimination and fractionally-rated power electronic converter at medium-speed operation [1]. The BDFIMs can be used in variable speed applications normally within a percentage above and below the so-called natural speed depending on the rating of the power converter. As a generator, it is particularly attractive for wind power generation as a replacement for doubly fed induction generators used in majority of wind turbines [2]. Other applications have also been reported for the BDFIM, for example, flywheel energy storage system [3] and ship generator [4].

The BDFIM consists of two stator windings designed with different pole-pair numbers, one is connected directly to the grid called the Power Winding (PW) and the other is supplied through a variable-voltage variable-frequency converter called the Control Winding (CW). A schematic of the BDFIM grid connection is shown in Fig. 1. The PW and CW pole-pair numbers are chosen in such a way to eliminate direct magnetic coupling between the two windings. The indirect coupling is enabled using a special rotor structure called the nested-loop rotor. The nested-loop rotor consists of several nestes, each having a number of loops. The number of nest required for the rotor can be obtained from:

$$
N_{n}=p_{p}+p_{c}
$$

where $p_{p}$ and $p_{c}$ are $\mathrm{PW}$ and $\mathrm{CW}$ pole-pair numbers, respectively.

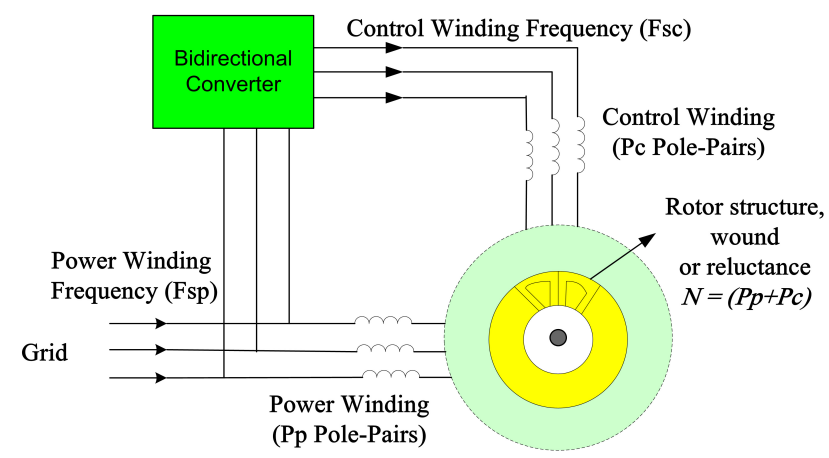

Fig. 1: The BDFIM grid connection. 
The BDFIM can operate in three distinct modes of operation including: induction, cascaded, and synchronous. In all modes the PW is directly connected to the supply, while the CW is opened in induction mode, shorted in cascaded mode and supplied through a fractionally-rated convertor in synchronous mode. The BDFIM rotational speed can be calculated by:

$$
\omega_{r}=\frac{\omega_{p}+\omega_{c}}{p_{p}+p_{c}}
$$

where $\omega_{p}$ and $\omega_{c}$ are PW and CW supply frequencies, respectively.

The fault detection methods in electrical machines are classified into signal-based and model-based techniques [5]. Among them, Motor Current Signature Analysis (MCSA) and vibration analysis are the most powerful techniques that can detect most of the faults including bearing faults, rotor misalignment and stator winding Inter-Turn Short Circuit (ITSC) faults [6]. The MCSA uses current sensors that are already available in most of the motor drive systems to measure stator current signals. Therefore, it would be a non-intrusive method with easy implementation and no additional costs [7].

The MCSA method relies on both time and frequency domain signal processing techniques in its analysis. Fast Fourier Transform (FFT) is one of the most common signal processing technique that takes the average of a signal in time domain and transfers the data to frequency domain [8]. Another form of signal processing technique is the timefrequency domain technique where both time and frequency domains are employed. Short-time Fourier transform is a more accurate version of FFT using a fixed window function, but it is unable to analyze the current signals at variable load and speed conditions, also suffering from high processing power requirement.

The wavelet transform method is a powerful signal processing method, which can overcome the above limitations that exist in different Fourier transform methods by using various scalable wavelet functions with alternative time and frequency domains [9]. It can also be adapted to a wide range of frequency and temporal resolution and has recently been used for detecting the ITSC faults in the stator winding of permanent magnet synchronous machines [10]. The advanced forms of the wavelet analysis i.e.. Discrete Wavelet Transform (DWT) with less computational time and continuous wavelet transform with higher accuracy, have also been reported for detecting faults in different electrical machines [11].

The main principle of DWT is the use of a series of bandpass filters that results in a small bandwidth (high frequency resolution and low time resolution) at low frequencies, and wide bandwidth (low frequency and high time resolution) at high frequencies. This is enabled by introducing a variable window width, such that it is decreased for higher frequencies by power of two. Therefore, the original signal passes through complementary filters and emerges as two signals termed as approximation and detail coefficients in wavelet analysis. The corresponding details are then used for fault detection purposes [9]. The most frequent faults in electrical machines are occurred in bearings, stator windings and rotor bars [12]. According to [6], the majority of the stator winding faults are ITSC faults caused by the deterioration of the stator winding isolation. Since the BDFIM has two sets of three-phase stator windings in common slots, the detection of the ITSC faults are crucial. In [13], and [14] a MCSA method based on the FFT analysis of the current signals has been introduced to detect stator winding ITSC fault and static eccentricity fault in the BDFIM, respectively. In those works, several frequency were introduced for detecting ITSC and static eccentricity faults by analysing the stator current spectra using FFT analysis in steady state operating condition.

In this paper the wavelet transform method is used to detect stator winding ITSC faults in a BDFIM by applying the DWT technique to the stator PW currents. The PW phase current is obtained by simulation and transferred to $\alpha \beta$ stator reference frame using Park transformation. Then, the $\alpha \beta$ current is analysed using DWT technique in order to detect the ITSC faults. It is shown in [9] that under unbalanced stator currents, a frequency of $2 f_{1}$ appears in $\alpha \beta$ current amplitude, where $f_{1}$ is the stator supply frequency. This frequency is considered as the ITSC fault index for the BDFIM.

The analytical winding function method have been developed for a prototype BDFIM in order to obtain the stator currents at different operating conditions. The ITSC fault detection method is then proposed based on wavelet transform analysis of the stator winding currents under healthy and fault conditions for various load levels. Finally, the proposed fault detection technique is validated using a Finite Element (FE) model of a D180 prototype BDFIM.

\section{PRototype BDFIM Model DEVElopMENT}

\section{A. D180 Prototype BDFIM}

Table I gives detailed information for the prototype D180 BDFIM used in this study. Fig. 2 shows the machine on the test plate. The rotor is a nested-loop design consisting of 36 slots. As it has $p_{p}=2$ and $p_{c}=4$, the rotor was constructed with $p_{p}+p_{c}=6$ nests terminated with a common end ring at one end only. Each nest is allocated 6 slots; therefore, three concentric loops are housed within each nest.

\section{B. Finite Element Model Development}

2-D FE linear models have been developed for D180 BDFIM using ANSYS Maxwell. The magnetic flux pattern in synchronous operating mode, presented in Table II, is shown in

TABLE I: Specifications for the D180 BDFIM.

\begin{tabular}{cccc}
\hline \hline Parameter & Value & Parameter & Value \\
\hline Stack length & $190 \mathrm{~mm}$ & Rated power & $7.8 \mathrm{~kW}$ at 750 \\
Rated torque & $100 \mathrm{Nm}$ & Efficiency & $>92 \%$ \\
PW no of poles & 4 & PW rated voltage & $240 \mathrm{~V}$ at $50 \mathrm{~Hz}$ \\
CW no of poles & 8 & CW rated voltage & $172 \mathrm{~V}$ at $25 \mathrm{~Hz}$ \\
Rotor type & Nested-loop & Rotor no of slots & 36 \\
\hline \hline
\end{tabular}




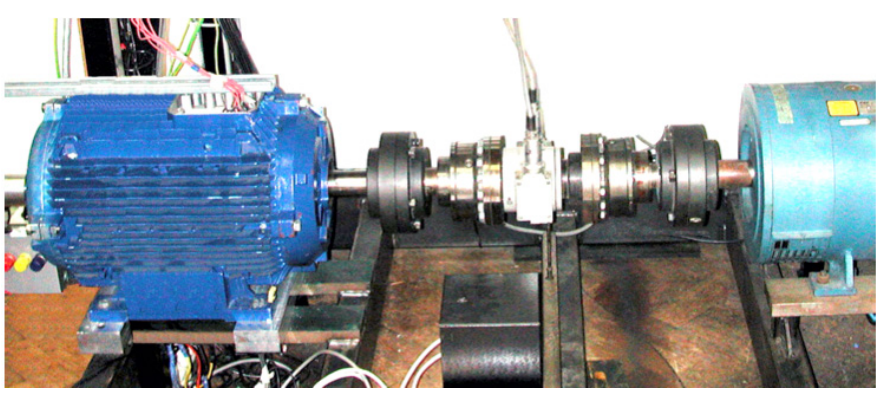

Fig. 2: D180 prototype BDFIM machine (left) on the test rig with torque transducer and DC load machine (right).

Fig. 3. The resulting PW and CW currents are compared with the experimental results in Fig. 4. Close agreement between the FE results and the experiment confirms the validity of the FE models. The FE linear model is particularly useful when it is used to verify the results obtained from analytical methods since the non-linear characteristics are ignored in both methods.

\section{Winding Function Method}

Winding function method is based on the coupled magnetic circuit theory and is used to calculate the machine inductances by means of the magnetic energy stored in the air-gap under both healthy and faulty conditions. The mutual inductance

TABLE II: Operating conditions for the simulations and experiments shown in Fig. 4.

\begin{tabular}{cccc}
\hline \hline Parameter & Value & Parameter & Value \\
\hline Torque & $103 \mathrm{Nm}$ & Speed & $750 \mathrm{rpm}$ \\
$V_{p w}$ & $204 \mathrm{~V}$ & PW frequency $f_{p w}$ & $50 \mathrm{~Hz}$ \\
$V_{c w}$ & $148 \mathrm{~V}$ & $\mathrm{CW}$ frequency $f_{c w}$ & $25 \mathrm{~Hz}$ \\
\hline \hline
\end{tabular}

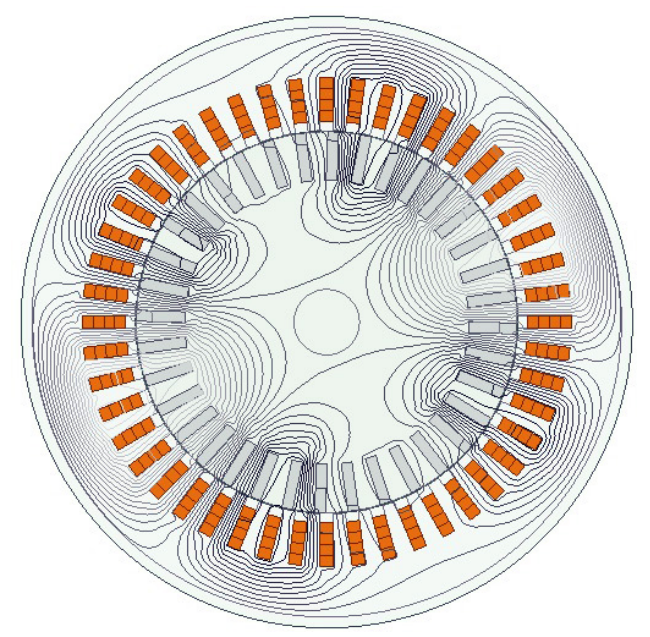

Fig. 3: Magnetic flux distribution of the BDFIM in synchronous operating mode.

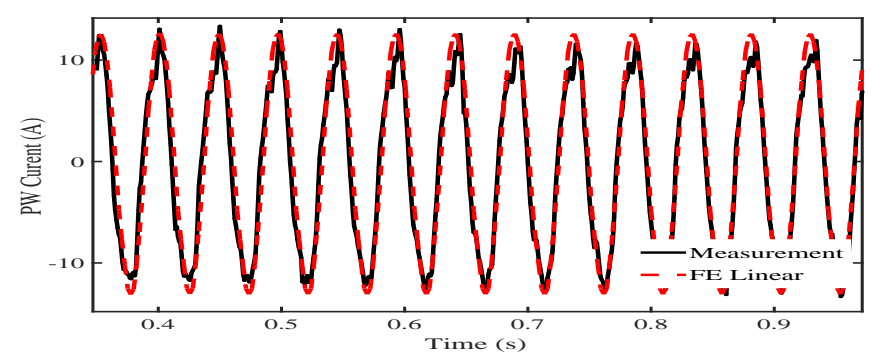

(a)

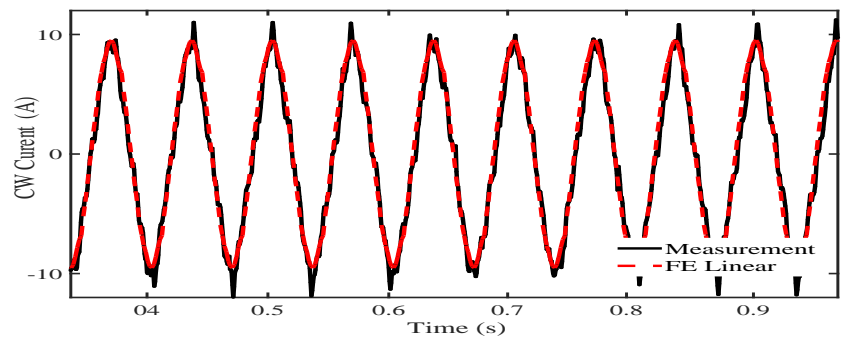

(b)

Fig. 4: D180 BDFIM Synchronous mode at Full-load condition $(\mathrm{T}=100 \mathrm{Nm}$ ) (a) PW current (b) CW current.

between the coils $A$ and $B, L_{A B}$, can be calculated as:

$$
L_{A B}=\mu_{0} r l \int_{0}^{2 \pi} n_{A}\left(\varphi, \theta_{r}\right) N_{B}\left(\varphi, \theta_{r}\right) g_{0} d \varphi
$$

where $n_{A}$ is turn function for coil $A$ and $N_{B}$ is winding function for coil $B, \mu_{0}$ is permeability of air, $l$ and $r$ are the machine stack length and rotor diameter, respectively, and $g_{0}$ is the machine's air-gap.

A winding function model has been developed for the D180 BDFIM which can be used to calculate PW and CW inductances under healthy and faulty conditions. Fig. 5 shows the mutual inductance between stator windings and rotor loops obtained by the winding function simulation. Once the PW and $\mathrm{CW}$ inductances are obtained, the couple circuit model is used to determine the PW and CW currents using the procedure discussed in [15].

\section{INTER-TURN SHORT CIRCUIT FAULT DETECTION TECHNIQUES}

Various diagnostic techniques have been used in ITSC fault detection of electrical machines including vibration analysis [16], negative-positive sequence impedance calculation [17], rotor field voltage analysis [18], stray flux measurements [17], Clarke transformation on stator voltages [19] and MCSA based method. Among them, the MCSA technique has been widely reported in the literature, specially for ITSC faults, as it offers significant advantages such as on-line monitoring, early fault detection, and low cost implementation over other techniques. Cira et al [20] have extracted negative and positive harmonics by applying FFT to space vectors of stator current and voltage to detect stator ITSC fault in permanent magnet synchronous motors. A modulation signal bi-spectrum has been used to detect stator winding faults for induction motors in [21] . A 


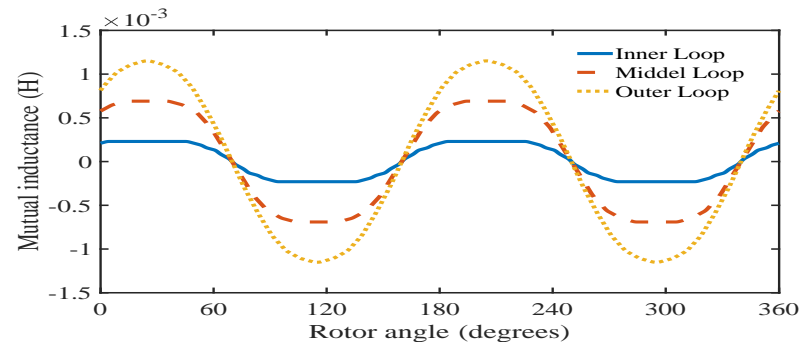

(a)

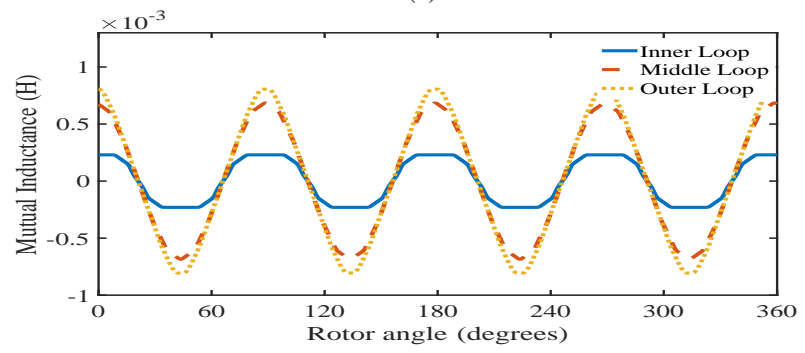

(b)

Fig. 5: Mutual inductances obtained from winding function method between (a) PW and nested-loop rotor bar (b) $\mathrm{CW}$ and nested-loop rotor bar.

new extended Park vector analysis has been proposed in [22] to detect short circuit winding faults in permanent magnet synchronous motor. Nevertheless, much attention has been recently paid to the wavelet transform analysis as a powerful signal processing technique for diagnosis of the ITSC faults in different electrical machines for example in [23] and [24]. The wavelet transform technique offers the analysis of nonstationary signals and under load variation. To the best of the Authors' knowledge no work has been reported on using the wavelet transform technique for detecting the ITSC faults in the BDFIMs.

Wavelet transform is a signal processing method which analyses a signal in high or low frequency details with high accuracy. The analysis uses Park vector transform, to transfer three-phase stator currents, $i_{s a}, i_{s b}$, and $i_{s c}$, into $\alpha \beta$ stator reference frame components, $i_{s \alpha}$ and $i_{s \beta}$, according to [9]:

$$
\begin{aligned}
& i_{s \alpha}=\sqrt{\frac{1}{6}}\left(2 i_{s a}-i_{s b}-i_{s c}\right) \\
& i_{s \beta}=\sqrt{\frac{1}{2}}\left(i_{s b}-i_{s c}\right)
\end{aligned}
$$

The instantaneous amplitude of the current in $\alpha \beta$ reference frame, $i_{s \alpha \beta}$ can then be obtained:

$$
\left|i_{s \alpha \beta}\right|=\sqrt{i_{s \alpha}{ }^{2}+i_{s \beta}{ }^{2}}
$$

It is shown in [9] that with unbalanced stator currents caused by ITSC faults, a harmonic component with a frequency of $2 f_{1}$ $\mathrm{Hz}$ appears in the spectrum of $\alpha \beta$ current amplitude, where $f_{1}$ is the stator winding supply frequency. This is also investigated using winding function method. The $\left|i_{s \alpha \beta}\right|$ frequency spectra resulted from the PW currents of the BDFIM in synchronous mode and under healthy and ITSC fault conditions are depicted in Fig. 6. The results are obtained when the PW is supplied by a $50 \mathrm{~Hz}$ voltage source and the $\mathrm{CW}$ is fed at $4 \mathrm{~Hz}$. As shown in Figs. 6b and 6c, under ITSC fault in either PW or $\mathrm{CW}$ an obvious harmonic component appears in the current spectra of the $\left|i_{s \alpha \beta}\right|$ at a frequency of twice the PW supply frequency, i.e.. $100 \mathrm{~Hz}$, whereas this harmonic component is not observed in healthy condition as depicted in Fig. 6a. It can hence be conducted that, this frequency can be used as ITSC fault index. Therefore, a wavelet detail coefficients containing $100 \mathrm{~Hz}$ frequency is utilized to detect ITSC fault in the BDFIM when PW is supplied through a $50 \mathrm{~Hz}$ voltage source.

The time step used in the simulations is $1 \mathrm{msec}$; therefore, the sampling frequency of the PW current is $1 \mathrm{kHz}$. Based on [9], the bandwidth captured in DWT analysis is half of the sampling frequency, i.e. $500 \mathrm{~Hz}$. The bandwidth of the current spectrum is then decomposed into smaller detail coefficients such that the bandwidth for each of them is halved after each scale. The bandwidth of the detail coefficients $\mathrm{d} 1$ to $\mathrm{d} 4$ are presented in Table III. Consequently, the BDFIM fault index frequency of $100 \mathrm{~Hz}$ falls in the third detail (d3) of wavelet decomposition. As a result, only $\mathrm{d} 3$ will be used in the subsequent analysis.

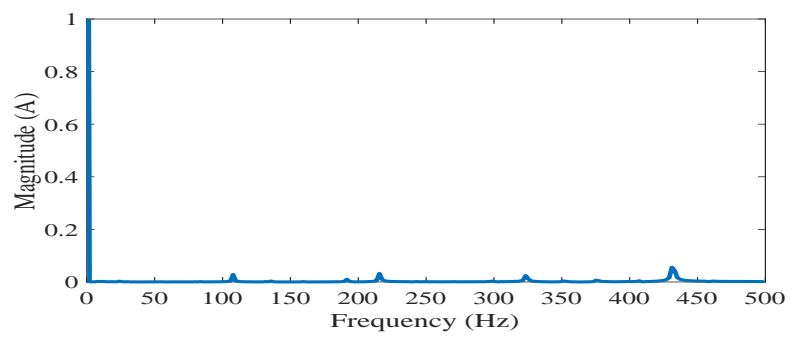

(a)

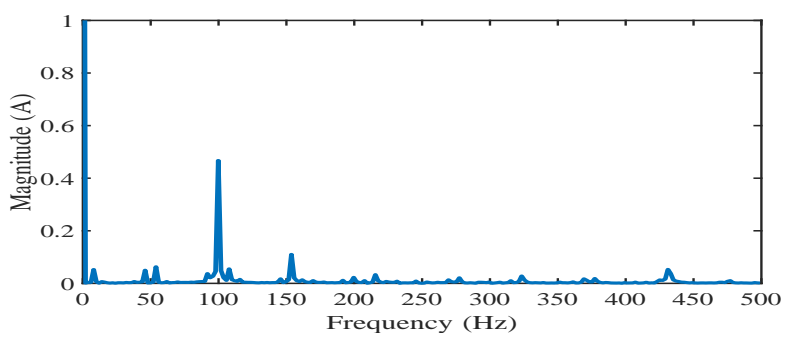

(b)

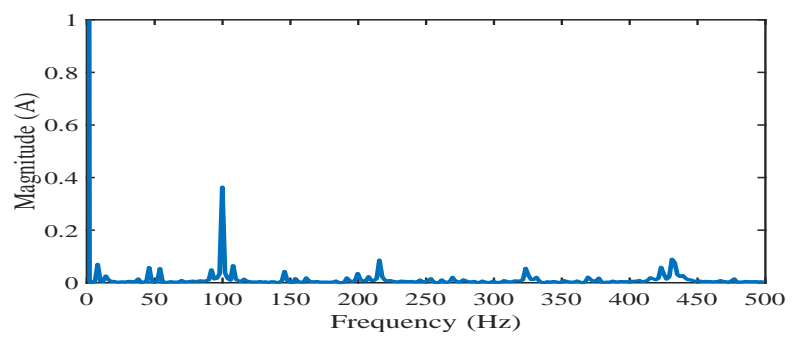

(c)

Fig. 6: $\left|i_{s \alpha \beta}\right|$ frequency spectrum under no-load condition (a) Healthy condition (b) $6 \%$ ITSC in PW (c) $6 \%$ ITSC in CW. 
The three-phase PW currents are obtained in healthy and faulty conditions using winding function method and FE analysis. The currents are then transformed to $\alpha \beta$ stator reference frame using (4) and their instantaneous amplitudes are calculated using (5). Then the wavelet detail coefficients are obtained using MATLAB software. By taking the RMS value of the detail coefficient in which the index frequency is located and comparing it to the same detail coefficient value obtained in healthy condition, the ITSC fault can be detected.

\section{RESULTS AND DISCUSSION}

The D180 BDFIM has been modelled under healthy and ITSC fault conditions using winding function method and FE analysis. The machine is operated in synchronous mode and at rated PW and CW voltages. The PW and CW frequencies are $50 \mathrm{~Hz}$ and $4 \mathrm{~Hz}$, respectively. Fig. 7 shows the wavelet detail coefficients of the PW currents obtained from FE analysis of the machine under $6 \%$ PW ITSC fault. The waveform in red color is the $\alpha \beta$ current, which is decomposed into its wavelet coefficients labeled with $\mathrm{d} 1$ to $\mathrm{d} 4$. The wave in black is $\mathrm{d} 3$ coefficient containing $100 \mathrm{~Hz}$ ITSC fault frequency index and will be used in the following analysis.

Figs. $8 \mathrm{a}$ and $8 \mathrm{~b}$ show the rms values of $\mathrm{d} 3$ coefficients of the $\left|i_{s \alpha \beta}\right|$ obtained by winding function simulations at different loads and PW and CW fault severity. The results are presented in per unit where the base values are the RMS values at healthy conditions. The results confirm that at all different levels of the mechanical loads, when an ITSC fault occurs, the magnitude of $\mathrm{d} 3$ coefficient increases significantly. It can also be seen

TABLE III: bandwidth values for each detail coefficients.

\begin{tabular}{cc}
\hline \hline Detail coefficients & Bandwidth $(\mathrm{Hz})$ \\
\hline $\mathrm{d} 1$ & $500-250$ \\
$\mathrm{~d} 2$ & $250-125$ \\
$\mathrm{~d} 3$ & $125-62.5$ \\
$\mathrm{~d} 4$ & $62.5-31.25$ \\
\hline \hline
\end{tabular}

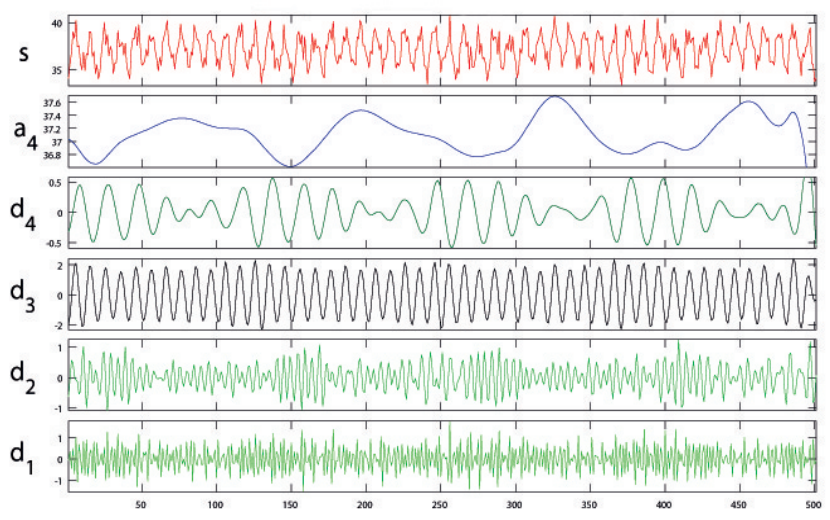

Fig. 7: Wavelet transform decomposition of the PW current of the BDFIM with $6 \%$ ITSC fault in PW.

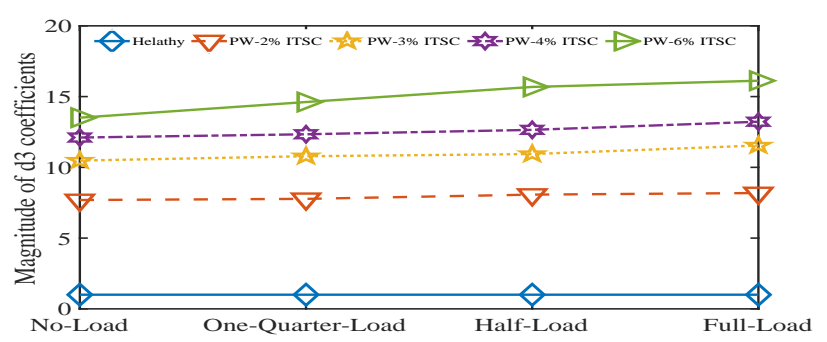

(a)

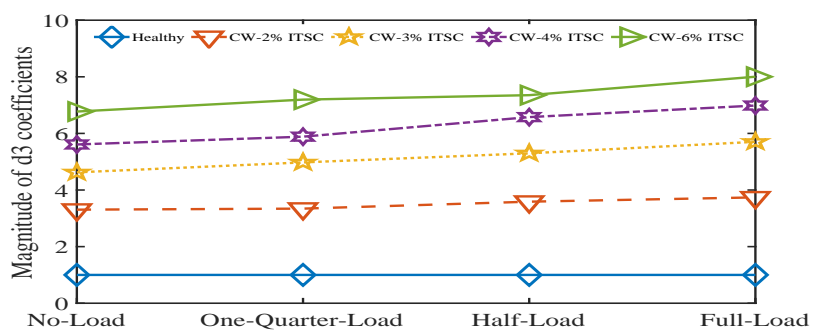

(b)

Fig. 8: The RMS values of $\mathrm{d} 3$ coefficients at various fault severity and load levels under (a) PW ITSC faults and (b) CW ITSC faults, obtained from winding function method.

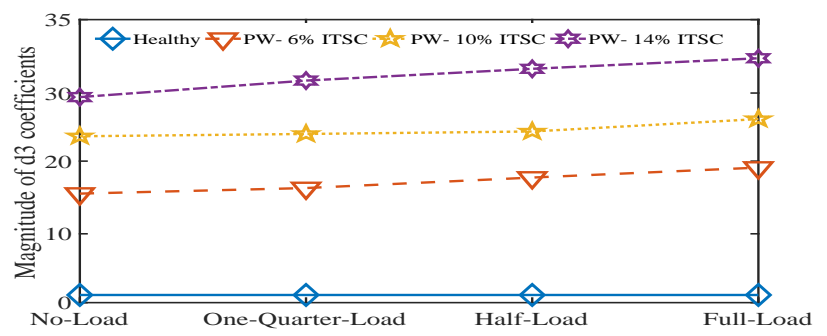

(a)

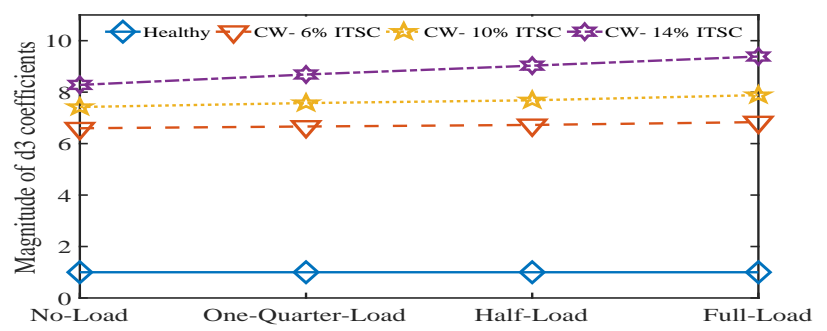

(b)

Fig. 9: The RMS values of $\mathrm{d} 3$ coefficients at various fault severity and load levels under (a) PW ITSC faults and (b) CW ITSC faults, obtained from FE analysis method.

that an increase in fault severity will result in an increase in the magnitude of the fault index at a given load condition. This means that the proposed method is able to detect ITSC fault in either PW or CW.

The above analysis has also been carried out using the PW currents obtained from FE analysis of the prototype BDFIM to investigate the validity of the proposed wavelet transform analysis. The $\mathrm{d} 3$ coefficient of the $\left|i_{s \alpha \beta}\right|$ obtained by FE 
analysis under ITSC fault in PW and CW are depicted in Figs. $9 \mathrm{a}$ and $9 \mathrm{~b}$, respectively. Similar conclusions can be drawn for $\mathrm{FE}$ analysis method where there are obvious increases in the magnitudes of the fault index at all different levels of machine's loads and fault severity.The following can be conculded from the simulation results:

1) Using the RMS values of $d 3$ coefficients, an ITSC fault, occurring in either PW or $\mathrm{CW}$, can be detected through comparing the RMS values of $\mathrm{d} 3$ coefficients with the same detail coefficient value obtained in healthy condition.

2) An increase in the ITSC fault severity level results in an increase in the magnitude of the fault index and $\mathrm{d} 3$ coefficients at a given load condition.

3) Mechanical load growth has little effect on d3 magnitude in comparison with an increase in the ITSC fault severity level. Therefore, this detail presents an effective method for ITSC fault detection in this machine.

\section{CONCLUSION}

A new fault detection technique based on wavelet transform analysis has been proposed in order to detect stator winding ITSC faults in the BDFIMs. The main advantage of the wavelet transform over other conventional fault detection methods is its capability to deal with speed and load variations. It has been shown that when an ITSC fault occurs in a BDFIM, a harmonic component with a frequency of twice the supply frequency can be detected in the $\left|i_{s \alpha \beta}\right|$ current spectrum. This frequency is used as the fault index and analyzed using wavelet transform technique. The PW currents of a prototype BDFIM have been obtained by winding function method and FE analysis at different mechanical loads and under healthy and fault conditions. It was shown that the occurrence of ITSC faults in either PW or CW will cause significant increase in the magnitude of the detail coefficient in comparison with the same parameter in healthy condition. The behavior of the detail coefficient at different load levels confirms the effectiveness of the proposed method for detecting ITSC faults in BDFIMs.

\section{REFERENCES}

[1] H. M. Hesar, H. A. Zarchi, and G. A. Markadeh, "Modeling and dynamic performance analysis of brushless doubly fed induction machine considering iron loss," IEEE Transactions on Energy Conversion, 2019.

[2] M. E. Mathekga, S. Ademi, and R. A. McMahon, "Brushless doubly fed machine magnetic field distribution characteristics and their impact on the analysis and design," IEEE Transactions on Energy Conversion, vol. 34, no. 4, pp. 2180-2188, 2019.

[3] A. C. Ferreira, R. M. Stephan, and M. R. M. Araujo, "Compensating characteristics of a brushless doubly-fed machine," in 2003 IEEE International Symposium on Industrial Electronics, vol. 1, pp. 375-378, 2003.

[4] F. Xiong and X. Wang, "Design and performance analysis of a brushless doubly-fed machine for stand-alone ship shaft generator systems," in 2011 International Conference on Electrical and Control Engineering, pp. 2114-2117, 2011.

[5] S. Mortazavizadeh and S. Mousavi, "A review on condition monitoring and diagnostic techniques of rotating electrical machines," Physical Science International Journal, vol. 4, pp. 104-122, 2014.

[6] V. Hegde and M. G. Sathyanarayana Rao, "Detection of stator winding inter-turn short circuit fault in induction motor using vibration signals by mems accelerometer," Electric Power Components and Systems, vol. 45, pp. 285-295, 2017
[7] A. Gandhi, T. Corrigan, and L. Parsa, "Recent advances in modeling and online detection of stator interturn faults in electrical motors," IEEE Transactions on Industrial Electronics, vol. 58, pp. 384-391, 2011.

[8] W. T. Thomson and M. Fenger, "Current signature analysis to detect induction motor faults," IEEE Industry Applications Magazine, vol. 7, no. 4, pp. 26-34, 2001.

[9] P. Barendse, B. Herndler, M. Khan, and P. Pillay, "The application of wavelets for the detection of inter-turn faults in induction machines," in 2009 IEEE International Electric Machines and Drives Conference, pp. 1401-1407. IEEE, 2009.

[10] J. Rosero, L. Romeral, J. Cusido, A. Garcia, and J. Ortega, "On the short-circuiting fault detection in a pmsm by means of stator current transformations," in 2007 IEEE Power Electronics Specialists Conference, pp. 1936-1941. IEEE, 2007.

[11] D. Gao, Y. Zhu, X. Wang, K. Yan, and J. Hong, "A fault diagnosis method of rolling bearing based on complex morlet cwt and cnn," in 2018 Prognostics and System Health Management Conference, pp. 196202. IEEE, 2018.

[12] G. Singh et al., "Induction machine drive condition monitoring and diagnostic researcha survey," Electric Power Systems Research, vol. 64, pp. 846-868, 2003.

[13] M. Afshar, A. Tabesh, M. Ebrahimi, and S. A. Khajehoddin, "Stator short-circuit fault detection and location methods for brushless dfims using nested-loop rotor slot harmonics," IEEE Transactions on Power Electronics, pp. 1-1, 2019.

[14] M. Afshar, S. Abdi, M. Ebrahimi, and S. A. Mortazavizadeh, "Static eccentricity fault detection in brushless doubly-fed induction machines based on motor current signature analysis," in IECON 2019-45th Annual Conference of the IEEE Industrial Electronics Society, vol. 1, pp. 13691374. IEEE, 2019

[15] R. McMahon, P. Roberts, M. Tatlow, E. Abdi, A. Broekhof, and S. Abdi, "Rotor parameter determination for the brushless doubly fed (induction) machine," IET Electric Power Applications, vol. 9, no. 8, pp. 549-555, 2015.

[16] Z. Yang, X. Shi, and M. Krishnamurthy, "Vibration monitoring of pm synchronous machine with partial demagnetization and inter-turn short circuit faults," in 2014 IEEE Transportation Electrification Conference and Expo (ITEC), pp. 1-6. IEEE, 2014.

[17] S. Cheng, P. Zhang, and T. G. Habetler, "An impedance identification approach to sensitive detection and location of stator turn-to-turn faults in a closed-loop multiple-motor drive," IEEE Transactions on Industrial Electronics, vol. 58, pp. 103-116, 2011.

[18] P. Neti and S. Nandi, "Stator interturn fault detection of synchronous machines using field current and rotor search-coil voltage signature analysis," IEEE Transactions on Industry Applications, vol. 45, pp. 103116, 2009.

[19] C. Bianchini, E. Fornasiero, T. N. Matzen, N. Bianchi, and A. Bellini, "Fault detection of a five-phase permanent-magnet machine," in 2008 34th Annual Conference of IEEE Industrial Electronics, pp. 384-391. IEEE, 2008

[20] F. Cira, M. Arkan, B. Gümüş, and T. Goktas, "Analysis of stator interturn short-circuit fault signatures for inverter-fed permanent magnet synchronous motors," in IECON 2016-42nd Annual Conference of the IEEE Industrial Electronics Society, pp. 441-454. IEEE, 2016.

[21] A. Alwodai, Y. Shao, X. Yuan, M. Ahmed, F. Gu, and A. D. Ball, "Inter-turn short circuit detection based on modulation signal bispectrum analysis of motor current signals," in 2013 19th International Conference on Automation and Computing, pp. 249-258. IEEE, 2013.

[22] M. S. Nejad and M. Taghipour, "Inter-turn stator winding fault diagnosis and determination of fault percent in pmsm," in 2011 IEEE Applied Power Electronics Colloquium (IAPEC), pp. 2203-2212. IEEE, 2011.

[23] W. Pietrowski and K. Górny, "Wavelet torque analysis and neural network in detection of induction motor inter-turn short-circuit," in 2017 18th International Symposium on Electromagnetic Fields, pp. 836-839. IEEE, 2017.

[24] U. Lal, P. Dutta, S. Kumari, and N. L. Nath, "Analysis of inter-turn short circuit fault in $2.5 \mathrm{hp}$ 3-phase induction motor," in 2016 IEEE First International Conference on Control, Measurement and Instrumentation (CMI), pp. 381-385. IEEE, 2016. 